\title{
Designing STEAM for Broad Participation in Science
}

\author{
Laura D. Carsten Conner ${ }^{1}$, Carrie Tzou², Blakely K. Tsurusaki ${ }^{2}$, Mareca Guthrie ${ }^{3}$, \\ Stephen Pompea ${ }^{4}$, Perrin Teal-Sullivan ${ }^{2}$
}

\author{
${ }^{1}$ Geophysical Institute and College of Natural Science and Mathematics, University of Alaska, Fairbanks, Fairbanks, AK, USA \\ ${ }^{2}$ School of Educational Studies, University of Washington, Bothell, WA, USA \\ ${ }^{3}$ University of Alaska Museum of the North, Fairbanks, AK, USA \\ ${ }^{4}$ National Optical Astronomy Observatory, Tucson, AZ, USA \\ Email:1dconner@alaska.edu
}

How to cite this paper: Carsten Conner, L. D., Tzou, C., Tsurusaki, B. K., Guthrie, M. Pompea, S., \& Teal-Sullivan, P. (2017). Designing STEAM for Broad Participation in Science. Creative Education, 8, 2222-2231. https://doi.org/10.4236/ce.2017.814152

Received: September 16, 2017

Accepted: November 14, 2017

Published: November 17, 2017

Copyright (c) 2017 by authors and Scientific Research Publishing Inc. This work is licensed under the Creative Commons Attribution International License (CC BY 4.0).

http://creativecommons.org/licenses/by/4.0/

(c) (i) Open Access

\begin{abstract}
The approach of integrating art with STEM, also known as STEAM (Science, Technology, Engineering, Art, and Math), has gained tremendous popularity over the last several years, in large part due its potential to enhance science learning and broaden participation in science (Vossoughi \& Bevan, 2014). However, the field is still nascent with respect to a guiding set of best practices. Unless close attention is paid to using meaningful STEAM practices, including those that support identity development and equity, STEAM is unlikely to fulfill its promise. In this essay, we present a new model for thinking about STEAM, including proposing a set of core STEAM practices that draw on disciplinary practices of art and science. We then provide two examples of STEAM practices in action with respect to activities that integrate biology and chemistry with art. Finally, we offer a set of design recommendations to those wishing to develop impactful STEAM activities. These principles are broadly applicable to science learning in diverse contexts and settings, both in and out of school.
\end{abstract}

\section{Keywords}

STEAM, Identity, Equity, Broadening Participation, Youth

\section{Introduction}

Broadening participation in STEM fields is widely acknowledged to be an important component of maximizing innovation, and is also an important social justice issue (e.g. National Science Foundation, 2013). Lifelong pursuit of 
STEM-related careers and hobbies has its ontogeny in sustained interest in science. However, it is well-documented that science interest sharply decreases around middle school age, particularly among girls and those from non-dominant cultures (Kahle et al., 1994; Jones et al., 2000; Murphy \& Whitelegg, 2006; Baram-Tsabari \& Yarden, 2010). This pattern is rooted in sociocultural practices that are generally embedded in formal learning settings, such as a strong emphasis on competition and performance, rather than on collaboration and growth (e.g. Tomlinson, 2013). Such practices are often at odds with the culture of many students (e.g. Brickhouse \& Potter, 2001; Carlone \& Johnson, 2007). Indeed, entering a science classroom has been likened to a "border crossing" into an unfamiliar culture (Aikenhead, 1996), where the majority of students do not see science as relevant to their interests and concerns (Aikenhead, 2001; Archer et al., 2012). Instead, they perceive science as something that is boring, uncreative, and passionless (Miller et al., 2006; Basu \& Calabrese Barton, 2007; Tsurusaki et al., 2017).

STEAM, the now widespread movement to integrate STEM (Science, Engineering, Technology, and Math) with art, has the potential to ease these border crossings and build interest and engagement in STEM, based on youth's widespread interest in art, design, and making (Vossoughi et al., 2016). Even though STEAM is a fairly new arena, there is already emergent evidence for significant impacts on youth with respect to a suite of outcomes associated with science learning, such as deepened engagement in STEM practices (Brahms, 2014), increases in interest, identity, and STEM content knowledge (Vossoughi \& Bevan, 2014) and development of design thinking (Peppler, 2013; Norris, 2014). In a program developed by the authors that merged art, biological, and physical sciences (Colors of Nature) the external evaluation found positive changes among participants $\left(5^{\text {th }}-7^{\text {th }}\right.$ grade girls) with respect to attitudes about science, interest in science, knowledge about the nature of science, self-concept of science ability, and self-concept of art ability (Larson et al., 2017). Additionally, our research showed that participating girls underwent identity shifts towards science through connecting science with everyday life and by seeing new ways in which art and science overlap (Tzou et al., 2014). In particular, girls started to articulate ways in which science uses creativity, and ways in which science and art were relevant to their everyday interests and concerns (Tsurusaki et al., 2017; Tsurusaki et al., 2017).

As illustrated above by the learning outcomes that are associated with STEAM, this approach holds vast potential for promoting learning and connecting diverse learners to the sciences. However, despite the explosion of activities labeled as "STEAM", the field currently lacks a well-articulated framework with respect to STEAM best practices. We posit that, without purposeful design and implementation, the impact of STEAM activities will be limited.

The purpose of this paper is to put forward a new model for thinking about STEAM, particularly as it applies to youth learning. While art and science each 
have well-defined practices in the literature at the K-12 level (e.g. Next Generation Science Standards and National Core Arts Standards in the U.S.A.) we know of no published attempts to define what "STEAM practices" should look like. In the sections below, we articulate a set of "STEAM practices," giving examples of how these practices play out within two concrete learning activities. We then put forward a set of STEAM design recommendations that follow from these practices. Our conceptions of STEAM derive from both the literature and from our experience in developing, testing, and iterating STEAM activities over the span of five years. While STEM and art taken together represent a wealth of subfields, encompassing everything from engineering to music, the ideas we put forward here are derived from our interdisciplinary focus on biology, the optical sciences, chemistry, and the visual arts (including drawing, graphic design, animation, etc., as defined in the National Core Arts Standards (National Coalition for Core Arts Standards, 2014)).

\section{STEAM Practices}

What does it mean to authentically do STEAM? Science and art are widely seen as distinct disciplines, with little overlap (Mishra \& Henriksen, 2012; Henriksen, 2014). Indeed, concrete differences between the two include art's emphasis on combining knowledge and personal experiences to make art, versus science's focus on a search for objective evidence to generate knowledge. Science tends to be evaluated by relatively systematic criteria, while art is often evaluated by context-dependent criteria. Science strives for repeatability while art often emphasizes uniqueness and even its idiosyncratic nature. However, scholars have documented a number of ways in which the two disciplines are similar (e.g. Root-Bernstein, 2003; Fulton \& Simpson-Steele, 2016). For instance, both disciplines use close observation of nature in order to generate questions. Artists, like scientists, create models as part of the process of developing and refining their work. Implicit in both disciplines is the employment of creativity to generate new ideas and products.

In our view, an authentic enactment of STEAM requires use of both science and art practices, but in a selective fashion that overlaps with identity-building practices. Thus, the STEAM practices that we set forth are a subset of science and art disciplinary practices that deeply incorporate scientific and artistic thinking, making, and experimentation in ways that intersect with learners' interests (Table 1). Activating interest and personal relevance among youth is the first step on a pathway towards deeper identification with science, which is central to developing life-long science engagement (National Research Council, 2009), and thus, is also central to broadening participation in science. One who identifies with science goes beyond "liking" science, but instead identifies as a person who is comfortable with, and uses, science in their everyday life. Practices that build science identity should thus be at the forefront of thinking when considering a STEAM approach that can broaden participation in science. 
Table 1. Core STEAM practices with intersections in science, art, and identity practices.

Core STEAM practices
Leveraging science concepts to create meaningful artwork
Focusing on outcomes that have a personal and/or aesthetic meaning
Conducting open exploration in the context of both science and art
Designing with intention (e.g., choices around medium, technique, and composition)
Iterating through several drafts, prototypes, or models
Communicating about process and outcome

Our STEAM model stresses leveraging science concepts in the service of creating art that has an aesthetic or personal meaning. What differentiates this from making a working model or prototype that is typical in science instruction is the added personalization of the artifact to a learner's own purposes or identities (Qi et al., 2016). Although a product is created in a STEAM activity, the disciplinary focus is on process, rather than the product itself, which acknowledges that the meaning in art emerges from engaging in the process rather than being limited to the product. This focus on process over product also helps promote self-compassion, rather than self-judgment, around the act of creating (e.g. Neff et al., 2005; Zabelina \& Robinson, 2010). It has long been recognized that youth become extremely self-critical of their own art around late elementary school age, and can stop participating as a result (Lowenfeld, 1957; Burton, 2009). Our STEAM practices have the potential to quiet the inner negative voice and allow youth to fully engage in the activity. Similarly, open exploration in concert with intentionality around design is critical in order to build a sense of agency, which is core to building a science identity (Murphy \& Hall, 2008) and can also serve to counteract negative self-judgement. This intentionality includes the use of genuine disciplinary tools from both art and science, as well as making choices about medium, technique, and composition in support of an artistic vision.

Iteration is another core STEAM practice. As Peppler and Hall (2016) argue, "trying to understand why designs fail and making changes so that it ultimately succeeds creates an opportunity for the learner to refine their understanding of the concept being modeled" (p. 143). Finally, communication to audiences in a way that conveys the personal and scientific meaning of the artwork is another critical STEAM practice. This act of creating and communicating allows students to connect their science/art making with everyday life, which is also important for building identity (Basu \& Calabrese Barton, 2007). Further, we argue that the motivation for communicating a message or meaning through artwork also pushes learners to refine and iterate their designs, reinforcing this core practice of both science and art. We believe that by incorporating these STEAM practices into the design of STEAM activities, we can help lower barriers to engaging in both science and art, promote views of science as creative rather than rote, and build identification with science among youth. The key to the creation of this type of STEAM activity is a coherent, intentional, and well-integrated 
combination of select art, science, and identity practices.

\section{Examples of STEAM Practices in Action}

We offer two examples from our own work which are illustrative of our approach. In the first example, we ask students to create a painting using red cabbage dye as the medium, after an iterative exploration of acid/base chemical reactions. In the second example, we ask students to storyboard and shoot a stop-motion animation that illustrates a fictional story based on a real biological function of color in nature (e.g. mimicry, camouflage, warning, or display). In both of these examples, the art produced by the learners not only represents an understanding of scientific principles such as $\mathrm{pH}$ or biological mimicry, but they are also personal and artistic expressions realized through the process of exploring possible visual outcomes, evaluating those outcomes, and making iterative, intentional, aesthetic decisions to create the finished artwork. In other words, learners materialize their understandings of scientific concepts in a creative form.

\subsection{Example 1: Painting with Chemistry}

In the red cabbage painting challenge, youth investigate how chemical reactions can affect color as they use acids and bases to change the color of the pigment (anthocyanin) in the red cabbage. They then apply this knowledge to create a color palette and several paintings. The learners begin by mixing baking soda and vinegar and observing the chemical reaction. After a discussion about acids and bases, they make observations of how these substances and other common acids and bases interact with test strips soaked in cabbage juice, focusing on color as an indicator. Patterns emerge according to whether a substance is basic or acidic. Using the knowledge gained during this observational period, they then use open experimentation to "mess around" with outcomes, followed by intentionally creating a color palette of specific colors they want to paint with. Learners also measure the $\mathrm{pH}$ of each substance in the palette in order to have some quantifiable measure around differences in color. Finally, the learners design and create a painting by applying the colors in their palette to paper coated with red cabbage extract. They then share their design choices with other learners during a gallery walk, in which they view and give feedback on each other's work.

This activity incorporates the key STEAM practices described above in several ways. First, learners leverage their scientific understanding of chemical reactions and indicators in the service of intentionally creating both artistic tools (the palette) and an artistic product (the painting). Open exploration of how different substances react with the cabbage juice is critical in terms of pattern discovery, and allows intentionality with respect to designing the palette. Students created paintings that were personally or aesthetically meaningful to them, rather than being told what to paint. Iteration was also critical. As the students created second or even third paintings, their observations of earlier outcomes led to a refinement 
of their palettes and further intentionality and control over the outcome. Through communication about the designs, students evaluated each other's choices and provided constructive feedback. In sum, their artwork represented an understanding of how chemical reactions can produce various colors and be used to paint something of personal interest.

\subsection{Example 2: Function of Color through Stop Motion Animation}

In the stop motion video design challenge, youth first explore and categorize different functions of color in nature by looking at many examples of coloration of organisms (plants \& animals) in nature. They learn about four specific biological functions of color-camouflage, warning, mimicry, and display-and why they are important for survival of individuals within a species. Emphasis is placed on the role of natural selection in driving the evolution of traits. The learners continue their exploration of this idea by choosing a biological function of color that they want to depict through the creation of a stop motion animation. They choose the "characters" (organisms), design the "backdrop" (environment that the organisms live in), and create a storyboard to plot the action across a sequence of frames. As they think through what will be depicted in each frame, they consider: 1) how the character(s) will move, 2) how the scenery will change, and 3) how the overall story depicts their chosen function of color. They determine the action for each frame (which consists of about 10 still pictures), and at the end of the storyboarding process they evaluate whether their movie communicates their intended message. After a tutorial in movie making software (e.g. iMovie), they set up their cameras to capture their animation. While shooting the animation, they systematically frame their shots, moving the camera and repositioning it so that it captures the background and characters in a way that is consistent with their storyboard. As they shoot the still frames, they need to constantly check to make sure their characters and backdrops are properly framed, as well as referring back to their plans to make sure they are telling the story according to their planned sequence of events. The learners then engage in iteration by evaluating and editing the movie with respect to framing, sequencing, and conceptual communication.

In this activity, we see an integration of the artistic processes of storytelling, framing, and character and background design in concert with the application of scientific knowledge about how color affects survival and reproduction of organisms. While the stop motion animations may involve fictional organisms (youth were not restricted to only using existing or known organisms in their animations), they were systematic and intentional about their use of specific functions of color. Thus, the animations allowed for open-ended expression and communication with respect to their choice of character, background setting, which particular trait they chose, and how they illustrated the function. At the same time, the activity design provided structure (number of photos per frame, setup of cameras, movie making software) to support success with the project. 
The end result is an animation that deeply applies a scientific idea to personally relevant artwork.

\section{Design Recommendations}

In sum, we argue that for STEAM to reach its full potential in promoting equity and broadening participation in science, close attention should be paid to incorporating the STEAM practices outlined in this essay into any activity labeled as "STEAM." The core practices we articulated in this essay are rooted in ideas about supporting the development of science identities, thus setting learners on a lifelong path of science learning in and out of school. In this final section, we offer some practical recommendations for instructional designers who wish to develop STEAM learning activities.

Recommendation 1: In designing a STEAM activity, draw on disciplinary practices of both science and art. Articulating which disciplinary practices and concepts are going to be represented should be the first step of designing a STEAM activity. We feel that the inclusion of the core STEAM practices we have identified above are critical. However, there are often opportunities to focus on additional science and art disciplinary practices in many STEAM activities. Mapping these practices to desired learning outcomes is a fruitful way to assure their inclusion.

Recommendation 2: Create spaces and places that offer opportunities for learners to engage in meaningful STEAM practice. In the sociocultural view of learning, the place, social context, and affordances of the setting are inseparable from the learning that takes place there (Bell et al., 2012). We suggest that learners have the chance to use genuine science and art tools, have opportunities to engage in open exploration rather than rote practice, and have the chance to discuss ideas and communicate with others about their work.

Recommendation 3: Use strategies that tackle the "inner negative voice" that can limit creativity and the willingness to engage or try. We suggest that the lurking presence of the inner negative voice be explicitly addressed. We also suggest the adoption of strategies that help calm this voice. Talk to learners about how the inner negative voice can shut down creativity, and how it can limit engagement. Include opportunities for iteration, so that students have more than one opportunity to achieve a desired outcome. In addition to being a core practice of art and science, iteration can help learners focus more on process rather than product. Break down tasks into manageable chunks, and employ meaningful constraints around challenges. These design choices help maximize creativity among learners.

Recommendation 4: Use practices that promote identification with science among diverse learners. In addition to integrating the core STEAM practices, find opportunities to illustrate how the content of your activity connects to everyday life. Give learners choices that promote agency and a sense of learner control. Find opportunities to position youth as emerging experts, such as providing 
opportunities for them to communicate to audiences of experts and/or peers. Explicitly identify how science is a creative endeavor, in contrast to commonly held beliefs.

\section{Conclusion}

In conclusion, we feel that the model we set forward in this essay has the potential to move the field of STEAM forward by offering: 1) an articulation of STEAM practices that represent intersections between science and art in a way that promotes identification with science; and 2) a set of best practices for designing and enacting STEAM activities. In our view, the best enactments of STEAM involve close attention to core practices of both art and science, rather than only using once of these disciplines in the service of the other. A critical piece of this approach is allowing learners to express science concepts through artwork that embodies the expression of personal and/or aesthetic meaning. The guidance we propose in our design recommendations should help allow educational designers to reach the often stated-goal of STEAM activities with respect to engaging learners in science, ultimately broadening participation in the field.

\section{Acknowledgements}

The development of the activities discussed within the manuscript as part of the Colors of Nature project was supported by the National Science Foundation under grant number DRL-1224020. Any opinions, findings, and conclusions or recommendations expressed in this material are those of the author(s) and do not necessarily reflect the views of the National Science Foundation.

\section{References}

Aikenhead, G. S. (1996). Science Education: Border Crossing into the Subculture of Science. Studies in Science Education, 27, 1-52.

https://doi.org/10.1080/03057269608560077

Aikenhead, G. S. (2001). Students' Ease in Crossing Cultural Borders into School Science. Science Education, 85, 180-188. https://doi.org/10.1002/1098-237X(200103)85:2<180::AID-SCE50>3.0.CO;2-1

Archer, L., DeWitt, J., Osborne, J., Dillon, J., Willis, B., \& Wong, B. (2012). Science Aspirations, Capital, and Family Habitus How Families Shape Children's Engagement and Identification with Science. American Educational Research Journal, 49, 881-908. https://doi.org/10.3102/0002831211433290

Baram-Tsabari, A., \& Yarden, A. (2010). Quantifying the Gender Gap in Science Interests. International Journal of Science and Mathematics Education, 9, 523-550. https://doi.org/10.1007/s10763-010-9194-7

Basu, S. J., \& Calabrese Barton, A. (2007). Developing a Sustained Interest in Science among Urban Minority Youth. Journal of Research in Science Teaching, 44, 466-489. https://doi.org/10.1002/tea.20143

Bell, P., Tzou, C., Bricker, L., \& Baines, A. D. (2012). Learning in Diversities of Structures of Social Practice: Accounting for How, Why and Where People Learn Science. Human Development, 55, 269-284. https://doi.org/10.1159/000345315 
Brahms, L. J. (2014). Making as a Learning Process: Identifying and Supporting Family Learning in Informal Settings. Doctoral Dissertation, Pittsburgh, PA: University of Pittsburgh.

Brickhouse, N. W., \& Potter, J. T. (2001). Young Women's Scientific Identity Formation in an Urban Context. Journal of Research in Science Teaching, 38, 965-980. https://doi.org/10.1002/tea.1041

Burton, J. (2009). Creative Intelligence, Creative Practice: Lowenfeld Redux. Studies in Art Education, 50, 323-337.

Carlone, H., \& Johnson, A. (2007). Understanding the Science Experiences of Successful Women of Color: Science Identity as an Analytic Lens. Journal of Research in Science Teaching, 44, 1187-1218. https://doi.org/10.1002/tea.20237

Fulton, L. A., \& Simpson-Steele, J. (2016). Reconciling the Divide: Common Processes in Science and Arts Education. The STEAM Journal, 2, 3. https://doi.org/10.5642/steam.20160202.03

Henriksen, D. (2014). Full STEAM Ahead: Creativity in Excellent STEM Teaching Practices. The STEAM Journal, 1, 15. https://doi.org/10.5642/steam.20140102.15

Jones, M. G., Howe, A., \& Rua, M. J. (2000). Gender Differences in Students' Experiences, Interests and Attitudes toward Science and Scientists. Science Education, 84, 180-192. https://doi.org/10.1002/(SICI)1098-237X(200003)84:2<180::AID-SCE3>3.0.CO;2-X

Kahle, J. B., \& Meece, J. (1994). Research on Gender Issues in the Classroom. In D. L. Gabel (Ed.), Handbook of Research in Science Teaching and Learning (pp. 543-557). New York, NY: Macmillan.

Larson, A., Danielson, J., \& Kealy, K. (2017). Colors of Nature Summer Academy Final Evaluation Report.

Lowenfeld, V. (1957). Creative and Mental Growth (3rd ed.). Oxford: Macmillan.

Miller, P. H., Blessing, J. S., \& Schwartz, S. (2006). Gender Differences in High-School Students' Views about Science. International Journal of Science Education, 28, 363-381. https://doi.org/10.1080/09500690500277664

Mishra, P., \& Henriksen, D. (2012). Rethinking Technology \& Creativity in the 21st Century: On Being In-Disciplined. TechTrends, 56, 18-21. https://doi.org/10.1007/s11528-012-0608-y

Murphy, P., \& Hall, K. (2008). Learning and Practice: Agency and Identities. Sage.

Murphy, P., \& Whitelegg, E. (2006). Girls in the Physics Classroom: A Review of the Research into the Participation of Girls in Physics. London: Institute of Physics Report.

National Coalition for Core Arts Standards (2014). National Core Arts Standards. http://www.nationalartsstandards.org/

National Research Council of the National Academies (2009). Learning Science in Informal Environments: People, Places, and Pursuits (336 p.). Washington DC: The National Academies Press.

National Science Foundation (2013). Committee on Equal Opportunities in Science and Engineering 2011-2012 Biennial Report to Congress Broadening Participation in America's STEM Workforce. https://www.nsf.gov/od/oia/activities/ceose/reports/Full_2011-2012_CEOSE_Report_t o_Congress_Final_03-04-2014.pdf

Neff, K., Hsieh, Y., \& Dejitterat, K. (2005). Self-Compassion, Achievement Goals, and Coping with Academic Failure. Self and Identity, 4, 263-287.

https://doi.org/10.1080/13576500444000317 
Norris, A. (2014). Make-Her-Spaces as Hybrid Places: Designing and Resisting SelfConstructions in Urban Classrooms. Equity \& Excellence in Education, 47, 63-77. https://doi.org/10.1080/10665684.2014.866879

Peppler, K. A. (2013). STEAM-Powered Computing Education: Using E-Textiles to Integrate the Arts and STEM. IEEE Computer, 46, 38-43. https://doi.org/10.1109/MC.2013.257

Peppler, K., \& Hall, T. (2016). The Make-to-Learn Youth Contest: Gaining Youth Perspectives on Learning through Making. In K. Peppler, E. R. Halverson, \& Y. B. Kafai (Eds.), Makeology: Makerspaces as Learning Environments (pp. 141-157). New York, NY: Routledge.

Qi, J., Dick, J., \& Cole, D. (2016). Paper Electronics with Circuit Stickers. In K. Peppler, E. R. Halverson, \& Y. B. Kafai (Eds.), Makeology: Makerspaces as Learning Environments (pp. 207-222). New York, NY: Routledge.

Root-Bernstein, R. S. (2003). The Art of Innovation: Polymaths and the Universality of the Creative Process. In L. V. Shavinina (Ed.), International Handbook of Innovation (pp. 267-278). Amsterdam: Elsevier.

Tomlinson, M. (2013). Education, Work, and Identity: Themes and Perspectives (pp. 107-129). New York, NY: Bloomsbury Academic.

Tsurusaki, B. K., Tzou, C., Carsten Conner, L. D., \& Guthrie, M. (2017). 5th-7th Grade Girls' Conceptions of Creativity: Implications for STEAM Education. Creative Education, 8, 255. https://doi.org/10.4236/ce.2017.82020

Tsurusaki, B. K., Tzou, C., Carsten Conner, L. D., Guthrie, M., \& Pompea, S. (2017). Colors of Nature: Art/Science Agency in Intersecting Figured Worlds. San Antonio, TX: National Association of Research in Science Teaching Annual International Conference.

Tzou, C., Conner, L., Guthrie, M., \& Pompea, S. (2014). Colors of Nature: Connecting Science and Arts Education to Promote STEM-Related Identity Work in Middle School Girls. In J. L. Polman, E. Kyza, D. K. O’Neill, I. Tabak, W. R. Penuel, A. S. Jurow, K. O'Connor, T. Lee, \& L. D'Amico (Eds.), Proceedings of the International Conference of the Learning Sciences 2014: Learning and Becoming in Practice (Vol. 3, pp. 1555-1556).

Vossoughi, S., \& Bevan, B. (2014). Making and Tinkering: A Review of the Literature (pp. 1-55). National Research Council Committee on Out of School Time STEM.

Vossoughi, S., Hooper, P. K., \& Escudé, M. (2016). Making through the Lens of Culture and Power: Toward Transformative Visions for Educational Equity. Harvard Educational Review, 86, 206-232. https://doi.org/10.17763/0017-8055.86.2.206

Zabelina, D. L., \& Robinson, M. D. (2010). Don't Be So Hard on Yourself: Self-Compassion Facilitates Creative Originality among Self-Judgmental Individuals. Creativity Research Journal, 22, 288-293. https://doi.org/10.1080/10400419.2010.503538 